\title{
The Preschool Child, Food Photography and a Parent's Bed: A Feasibility Study to Determine Acceptable Visual Data Collection Methods
}

\author{
McSweeney $\mathrm{L}^{{ }_{1}}$, Rapley $\mathrm{T}^{2}$ and Adamson $\mathrm{A}^{1}$
}

${ }^{1}$ Institute of Health and Society and Human Nutrition Research Centre, Newcastle University, Framlington Place, Newcastle, NE2 4HH, UK

${ }^{2}$ Institute of Health \& Society, Newcastle University, Richardson Road, Newcastle, NE2 4AX, UK

${ }^{*}$ Corresponding author: McSweeney L, Institute of Health and Society and Human Nutrition Research Centre, Newcastle University, Framlington Place, Newcastle, NE2 4HH, UK, E-mail: lorraine.mcsweeney@ ncl.ac.uk

Citation: McSweeney L, Rapley T, Adamson A (2015) The Preschool Child, Food Photography and a Parent's Bed: A Feasibility Study to Determine Acceptable Visual Data Collection Methods. J Nutr Health Sci 2(4): 406. doi: 10.15744/2393-9060.2.406

Received Date: October 15, 2015 Accepted Date: November 23, 2015 Published Date: November 25, 2015

\begin{abstract}
In the UK, one in four children are starting school overweight. It has been proposed that early childhood provides a unique opportunity within which to establish lifestyle behaviours that will promote health and minimise the risk of development of fatness. Preschool settings may provide valuable opportunities to access children and their families not only for promoting healthy lifestyles, but also to develop and evaluate behaviour-change interventions. The Study of Kids in Preschool was a feasibility study conducted in four preschools in the North East of England to determine which data collection methods and tools would be acceptable to parents and children. To include the children in the data collection process, provide additional qualitative insights and validate the parentcompleted food diaries; children, in all four preschools, were provided with digital cameras to record their food consumption over the four day data collection period. The use of digital cameras to record dietary intake has been trialled with older children but few studies exist with children aged 3-5 years.

Of the 121 families registered at the preschools, 36 parents consented to participate. Twenty-six parents ( $72 \%)$ completed the food diary and 23 children/families took photographs. In comparison with the food diaries it was apparent that not all the eating occasions were recorded and were mostly of meals rather than snacks and drinks. Two-hundred and seventy-three photos were recorded, 204 (75\%) were of food items. It was possible to determine the context of the eating occasion in 60 of the photos and portion size could be estimated in 169 of the photos. The photographs were visually assessed using content analysis and coded. Parents provided feedback of the methods via questionnaire. Despite the range of approaches undertaken, the activity demonstrated that the children and parents were able to engage with the task that was meaningful for them.
\end{abstract}

Keywords: Visual data collection methods; Preschool children; Feasibility study; Food photography

List of abbreviations: UK: United Kingdom; PSA: Public Service Agreement; SKIP: Study of Kids in Preschool; FAST: Food Assessment in Schools Tools; NDNS: National Diet and Nutrition Survey

\section{Introduction}

Globally, it was estimated that in 2010, 43 million preschool children in developing and developed countries were overweight or obese, with a further 92 million estimated to be 'at risk' of overweight; as defined by the World Health Organization Growth Standard [1]. In the UK one in four children are starting school overweight [2]. Overweight 2-5-year-olds are at least 4 times more likely than their lean peers to become overweight adults [3]. It is more difficult to reduce excessive weight-gain in adolescents and adults than in childhood, therefore, there is growing consensus that obesity prevention strategies in early childhood may be key [4]. Campbell and Hesketh [5] propose that 'early childhood provides a unique opportunity within which to establish lifestyle behaviours that will promote health and minimise the risk of development of fatness' [5p. 328]. However, whilst there have been numerous obesity prevention interventions conducted in primary schools, there is a lack of interventions targeting children in preschool settings in the UK. 
A number of influential independent reviews commissioned by the government have highlighted the importance of early intervention and support for families with young children [6-10]. As part of a 2007 government strategy to reverse the obesity trend, a Public Service Agreement (PSA) to improve the health and wellbeing of children and young people was established [11], this aims to reduce the percentage of obese and overweight children to 2000 levels by 2020 [12]. The UK has become the highest spender on early years services in Europe [13]. In 2012, 98\% of the 3-4 year old population benefited from some free early education at maintained schools or in the private, voluntary or independent sector [14]. It follows then, that preschool settings may provide valuable opportunities to access children and their families not only for promoting healthy lifestyles, but also to develop and evaluate behaviour-change interventions $[15,16]$.

In the research community it has become more accepted that children should be included in data collection and given a 'voice' $[17,18]$ and this is where visual methods may be appropriate. The use of visual data methods is considered to be especially appropriate in studies relating to diet and physical activity. Everyday activities such as eating are often carried out without reflection; asking participants to visually record their dietary consumption enables a different way of 'seeing. In addition it is thought that the sensory and visual nature of food may be better captured via visual methods [19]. Photographs can provide additional insight and context into the population being studied such as gaining an insight into family dynamics [19] and such factors as social class [20]. It has been questioned whether collecting visual data such as photographs and drawings just 'adds' more data [21] and it has been acknowledged that the organisation, storage, sharing of images, and time needed to analyse multiple visual data can be challenging [19]. Despite the challenges, O'Connell [19] believes that visual data can do more than just corroborate other qualitative data such as interviews; it can complement the data providing a fuller picture which helps to bring the research 'alive' for policy makers and practitioners. Furthermore, Sharples, Davison [22] argue that children's photographs are not just a view of their world but are a construction of their identity in relation to their parents and peers. The use of digital cameras to record dietary intake has been trialled in several studies with older children [23-26] but very few studies exist with preschool-aged children.

The Study of Kids in Preschool (SKIP) was a feasibility study conducted in four nursery schools in the North East of England. The purpose of the study was to determine whether a practitioner-led intervention that has the aim of improving lifestyle behaviours in preschool children (age 3-5 years) and their families, thus reducing overweight and obesity risks would be acceptable and practical in a nursery environment. A feasibility study was conducted to determine which data collection methods and tools would be acceptable to parents and children. This paper describes the dietary measures and focuses on the visual data captured by the children.

\section{Materials and Methods}

\section{Participants}

Four local authority nursery schools in the North East of England were recruited to the SKIP study. A sample size of four schools is considered to be sufficient for a feasibility study, the NHS [27] state that the sample size should be adequate to estimate the critical parameters for example, the recruitment rate. Lancaster, Dodd [28] maintain that as a 'rule of thumb' 30 participants are required to estimate a parameter. The four nursery schools (combined) provided places for 121 children. Parents were provided with a study information sheet and were later invited to participate in the study at parent recruitment sessions which were held at the preschool drop-off and collection times. Of the 121 families 36 parents in total volunteered and consented to take part in the study (30\% response rate). The four schools were randomised into ( 2 of each) intervention schools and wait list/control schools (described elsewhere). The intervention schools had 43 children on their register and the wait list schools 78 children; 15 families were recruited in the intervention schools (35\%) and 21 in the wait list (27\%). Half the children (18/50\%) were girls, 13 (36\%) parents had some additional training after leaving school (such as college) and 7 (19\%) a university degree. The majority of parents reported being married or cohabiting (25/69\%). Most of the children were aged 3 years (29/81\%). None of the children in the intervention schools attended a full-day session although some children in one nursery left or arrived after/before lunch and parents provided a pack-lunch. Just under half of the wait list children (19/52\%) attended a full-day nursery session; although some of the children in one of the schools attended nursery full-time for two and half days a week only.

\section{Data collection packs}

The participating families were issued with a data collection pack (to be completed over 2 week days and the weekend) which included a parent-completed diary to capture the child's dietary consumption; TV viewing - this was a proxy measure for sedentary behaviour; and time the family spent together in 'active' pursuits. To measure the child's physical activity each child was provided with an accelerometer or pedometer and, centrally for this paper, each child received a digital camera.

\section{Dietary measurement methods}

There are many methods used to collect dietary data from a specified population. The gold standard methods are considered to be bio-markers and doubly-labelled water; however, these methods are labour-intensive, expensive, are only available for a limited range of nutrients and can be intrusive for the participant [29,30]. The most common methods used in health research are selfcompleted questionnaires which include 24 hour recall, food frequency questionnaires, checklists and weighed diaries. Measure- 
ment of dietary intake is complex and the most appropriate method will depend on: the objectives of the surveillance; the type of data required; available resources and the population of interest [31]. Consequently, a number of tools have been developed in intervention studies with children and/or adults. Young children are unable to record their own dietary consumption; therefore, a tool that can be completed by a parent or care-giver is required. One such tool is the Food Assessment in School's Tool (FAST) [32]. The FAST tool was developed and validated by Newcastle University in Collaboration with Dundee University to allow access to the diets of large groups of primary age school children. The tool incorporates elements of a food diary and a food frequency questionnaire. Each day in the diary is divided into six time slots:

1. 6.00 am to $9.00 \mathrm{am}$

2. 9.01 am to $11.00 \mathrm{am}$

3. 11.01 am to $2.00 \mathrm{pm}$

4. $2.01 \mathrm{pm}$ to $4.00 \mathrm{pm}$

5. $4.01 \mathrm{pm}$ to $7.00 \mathrm{pm}$

6. $7.01 \mathrm{pm}$ to $11.00 \mathrm{pm}$

Each time slot contains a pre-printed list of frequently consumed foods with a space for ticking; each time slot also contains a section of blank lines for writing in other unlisted foods. The list of foods was determined from the National Diet and Nutrition Survey (NDNS) database [33,34]; this enabled a selection of the foods most commonly eaten in each time slot. The NDNS survey data for children aged 3 to 7 years was used to determine standard age and sex specific portion sizes [35]. It was determined that this method would be feasible in the targeted population for the SKIP study. To provide context to the FAST diaries, the children were provided with small, easy-use digital cameras (model: Vivitar 4090) to record their food consumption over the measurement period. A digital camera may provide documentation of what and how much is being eaten and the context of the eating occasion, be it, at home at a table, at a restaurant and so on [26]. It has been suggested that the use of visual data methods may be appropriate for the study of 'everyday' occurrences that is, seeing taken for granted routines in a new light, in this case from a child's perspective. Furthermore, visual methods may be more acceptable to certain social groups such as children [19]. In comparison with diet diaries, a photographic record does not offer any more accuracy; however, in conjunction with a food diary it could improve accuracy. Furthermore, it is a tool that can be used by preschool children providing additional qualitative insights and including them in the data collection process. The parents were provided with an information sheet explaining why the child had been provided with a camera and asking that they support the child in making sure the camera was accessible at meal/snack times and to assist them if necessary. The researcher prompted the child to take photographs whilst at preschool.

\section{Data management and analysis}

Images were downloaded and stored securely in digital files in a password protected programme. The photographs were analysed using visual content analysis. This is a systematic and objective method of describing and analysing, written, verbal or visual communication messages and has a long history of use in communication, journalism, sociology, psychology and business [36]. Feedback about the methods was collected via questionnaire (parents) and interviews (nursery teachers) which was analysed thematically. Nvivo [37] qualitative management software was used in indexing and coding of data and themes.

\section{Ethical issues}

Participation was entirely voluntary; however, due to the age of the children, consent was provided by parents only thus allowing the potential for parents to coerce their children to adhere to the tasks. The captured images could be viewed on the cameras prior to download, therefore, parents were able to delete any images they did not want the researcher to view. Interview transcripts and the questionnaires were anonymised and treated in the strictest of confidence. All direct identifying information was removed from the transcripts by giving each participant a unique code number which was used to attribute comments during analysis. The study received ethical approval from Newcastle University Faculty of Medical Sciences Ethics Committee.

\section{Results}

The findings comprise an evaluation of the photographs recorded by the children and the views of the child photography method from nursery staff and parents. The FAST diaries were completed by the parent whilst the child was at home and by one researcher when the child was attending their nursery session. The families were encouraged to transfer the camera between home and nursery so that the children could photograph foods consumed at nursery; however, many families forgot to do so. Twenty-six (72\%) of parents completed the FAST diary and 23 (64\%) of children/parents took photographs, although not all eating occasions were photographed as illustrated in Figures 1 and 2. Figure 1 shows an example of a completed one day FAST diary page in comparison with the photographs recorded by the child (Figure 2). It can be seen that the child photographed part of their breakfast, their lunch and evening meal. The only 'snack' photographed was the gingerbread man; other snacks, fruit and drinks were not photographed. The tendency to only photograph meals appeared to be a common phenomenon. This was perhaps due to snacks not being thought of as food per se, or that such a relatively unstructured, informal event, with the addition of little preparation time, did not trigger the parents or child to think of taking a photograph. Additionally, they may have been more likely to be consumed away from the home environment, and so the family did not have the camera with them. 


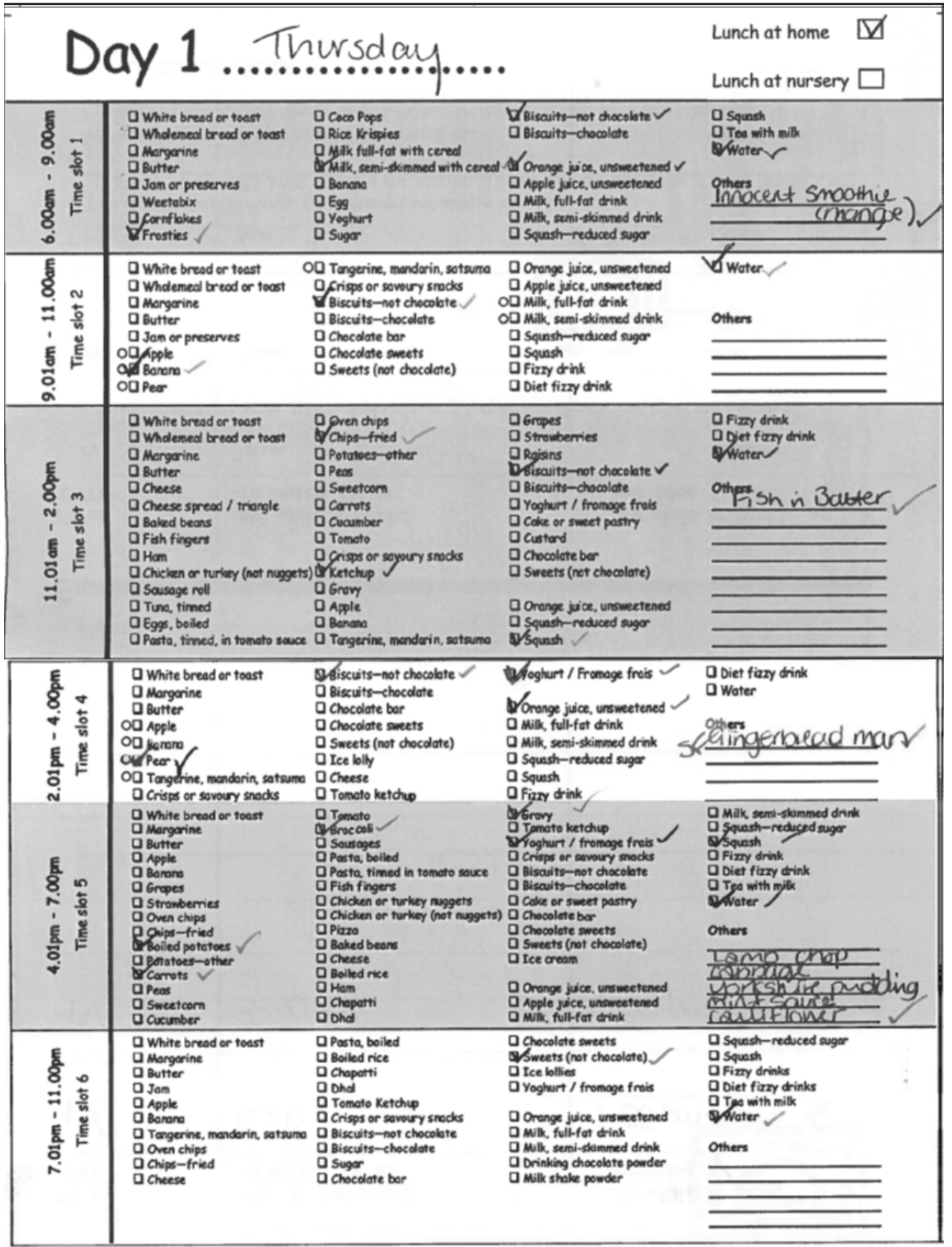

Figure 1: Example of child's one day Food Assessment in School's Tool diary

In order to conduct an analysis of the photographs, the eating occasions were visually assessed using content analysis and coded. The children's photograph activity provided additional information and gave context to the food diaries, such as whether the food was consumed at a table etc. Although many children engaged with the task, it was apparent that the activity instructions were not always followed; for example children took photographs of other objects such as the TV or the garden, one child even photographed his parent's bed. Moreover, some parents photographed their child with the meal/food. However, despite the range of approaches undertaken, the activity demonstrated that the children and parents were able to engage with the task in a way that was meaningful for them. Table 1 summarises the findings of the photographic analysis.

As shown in Table 1, in total 273 photos were recorded, 204 (75\%) of which were of food items. In 60 of the 204 food photos it was possible to determine the context of the eating occasion; examples included eating at a table, on tray, on the floor and away from the home environment. Portion sizes too, could be visually estimated in 169 of the photographs. Sixteen fruit eating occasions we- 
re photographed over the 4 -day period by 7 (30\%) children (not shown). Eight (35\%) children photographed 13 vegetable occasions, over the 4-day period, some of which were school lunches. In contrast, analysis of the FAST diaries revealed that $92 \%$ of children were reported to have eaten fruit and $77 \%$ vegetables over the four day period. However, not all eating occasions were photographed. Meals eaten away from the home environment were identifiable in 7 photographs; they included lunch or snack eaten at nursery and 1 occasion of chips in a café/fish shop. Table 2 illustrates individual accounts of 2 children/family's photos recorded over the 4-day period and highlights the type of foods eaten in which context. These children were 2 of the 7 who photographed fruit, however, it can be seen that neither child recorded any vegetable or salad consumption.
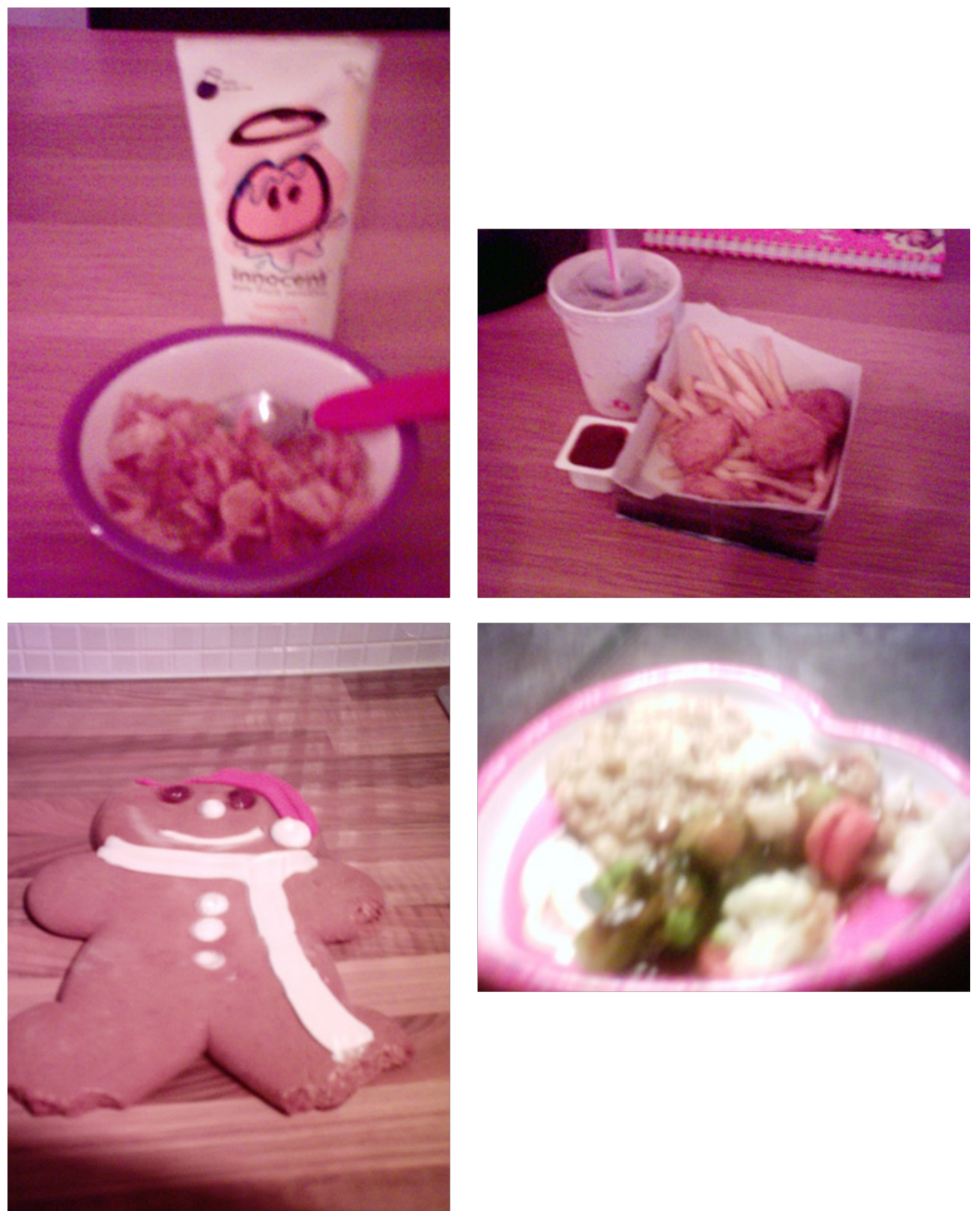

Figure 2: Child’s one day photographed eating occasions

As this was a feasibility study to determine if young children and their families were willing and able to capture data using digital cameras, no further analysis of the photographs was conducted.

\section{Dietary methods feedback}

Parents were asked to provide feedback on the intervention methods via questionnaire. Despite evidence of completed tasks by families only $35 \%$ of parents returned the feedback questionnaires. The majority of parents reported being happy to complete the FAST diary. A couple of parents commented that they sometimes struggled to find time to complete the diary every day. Completing the diary highlighted family habits:

Very good, it was interesting and made us more aware of the family and child eating. I enjoyed it (CC32). 


\begin{tabular}{|c|c|c|c|c|c|c|}
\hline $\begin{array}{l}\text { Child ID } \\
(n=23)\end{array}$ & $\begin{array}{l}\mathrm{n}=\text { photos } \\
\text { (over } 4 \text { days) }\end{array}$ & Food photos & $\begin{array}{l}\text { Non-food } \\
\text { photos }\end{array}$ & $\begin{array}{l}\text { Unclear } \\
\text { images }\end{array}$ & $\begin{array}{l}\text { Context } \\
\text { Clear }\end{array}$ & $\begin{array}{l}\text { Portion Size } \\
\text { estimation } \\
\text { Clear }\end{array}$ \\
\hline 010 & 20 & 15 & 5 & 1 & 1 & 0 \\
\hline 011 & 8 & 5 & 2 & 1 & 2 & 5 \\
\hline 012 & 17 & 2 & 4 & 11 & 0 & 1 \\
\hline 013 & 5 & 2 & 1 & 2 & 0 & 2 \\
\hline 014 & 9 & 8 & 1 & 0 & 3 & 3 \\
\hline 015 & 16 & 13 & 1 & 2 & 2 & 2 \\
\hline 016 & 10 & 6 & 0 & 4 & 4 & 4 \\
\hline 017 & 5 & 4 & 0 & 1 & 0 & 3 \\
\hline 021 & 26 & 16 & 4 & 6 & 5 & 9 \\
\hline 022 & 17 & 17 & 0 & 0 & 9 & 11 \\
\hline 023 & 13 & 13 & 0 & 0 & 3 & 7 \\
\hline 024 & 1 & 1 & 0 & 0 & 0 & 1 \\
\hline 025 & 5 & 4 & 1 & 0 & 3 & 2 \\
\hline 026 & 29 & 19 & 0 & 10 & 2 & 12 \\
\hline 027 & 10 & 3 & 0 & 7 & 1 & 1 \\
\hline 032 & 3 & 1 & 0 & 2 & 1 & 1 \\
\hline 034 & 3 & 3 & 0 & 0 & 2 & 3 \\
\hline 036 & 26 & 22 & 1 & 3 & 18 & 16 \\
\hline 037 & 4 & 1 & 3 & 0 & 1 & 1 \\
\hline 041 & 5 & 5 & 0 & 0 & 1 & 1 \\
\hline 043 & 6 & 3 & 2 & 1 & 1 & 3 \\
\hline 045 & 2 & 0 & 2 & 0 & 0 & 0 \\
\hline 049 & 33 & 32 & 0 & 1 & 2 & 27 \\
\hline TOTAL & 273 & 204 & 29 & 40 & 60 & 169 \\
\hline
\end{tabular}

Table 1: Number and context of photos recorded by children/family over 4 days

The provision of cameras to the children was acceptable by most parents; however, one mother who had five children was reluctant to leave the camera unattended 'in case it got broken'. Another mother reported the use of the camera to be a positive aspect:

Good idea, my child loves taking photos and it enabled her to feel part of the project (CC34).

The ability of the project to enable the children to feel included in the data collection process was one of the objectives.

Staff feedback was an ongoing process through observations and informal discussions during the intervention period. At intervention end, the nursery teachers (NT) consented to an interview. One staff member reported that some parents forgot to use the camera. Moreover, one parent had told the staff member that she was unable to complete the food diary 'because her child did not want her to. The NT felt that the parents did not appreciate the importance of completing the data collection tasks:

It gave us a bit of an eye opener when we had parents coming in and saying they [the child] won't do this and they won't do that and you think [laughter] they will you know! It helped us see things that were nothing to do with the project (NS1)

It was suggested that perhaps a meeting with the parents prior to the data collection period would have enabled the staff to emphasise the importance of completing the tasks resulting in better adherence. One staff member from another preschool centre felt the recording of the child's school packed lunch unnecessary as the preschool policy was that any un-eaten food was sent home with the child so the parent would 'know what the child had eaten'. However as observed by the researcher this was not always the case as food items were often dropped on the floor and were subsequently binned. The staff member appeared unaware that the task was not purely for recording the child's dietary consumption but also to involve the child in the data collection process. She later reported that she felt the methods were not age-appropriate for the children. However, this was an isolated view as the majority of staff members encouraged child involvement and reported positive aspects of the tasks:

From the uptake a lot of the families seemed as if they really enjoyed it with the children and were proud of what they had done... (NS1)

The family involvement extended to several aspects of the intervention. 


\begin{tabular}{|c|c|c|c|c|c|c|}
\hline Child ID & Food & Drinks & Context & Portion size estimation & Other & Notes \\
\hline 022 & $\begin{array}{l}\text { Porridge } \\
\text { Sandwich wrap } \\
\text { Crisps } \\
\text { Houmous } \\
\text { Crisp bread } \\
\text { Filled pasta in } \\
\text { sauce } \\
\text { Toast and jam } \\
\text { Fromage frais } \\
\text { Soup } \\
\text { Sandwich wrap } \\
\text { Fish finger } \\
\text { Breaded item } \\
\text { Chips } \\
\text { Toast and jam } \\
\text { Apple } \\
\text { Banana } \\
\text { Yoghurt } \\
\text { Raisins } \\
\text { Weetabix and } \\
\text { milk } \\
\text { Apple } \\
\text { Unknown } \\
\text { Malteasers } \\
\end{array}$ & $\begin{array}{l}\text { Milk Liquid } \\
\text { in coloured } \\
\text { cup }\end{array}$ & Home & Clear in 11 of 22 photos & 0 & $\begin{array}{l}\text { This child/family provided } \\
\text { a good record of the food } \\
\text { items given to the child } \\
\text { over the } 4 \text {-day period. They } \\
\text { were unusual in that they } \\
\text { remembered to photograph } \\
\text { snacks as well as meals } \\
\text { which many families } \\
\text { omitted to do. }\end{array}$ \\
\hline 023 & $\begin{array}{l}\text { Cereal hoops } \\
\text { Banana } \\
\text { Pasta with } \\
\text { tomato sauce } \\
\text { Satsuma } \\
\text { Fish and chips } \\
\text { Banana } \\
\text { Ham sandwich } \\
\text { portion } \\
\text { Slice of pork } \\
\text { and egg pie } \\
\text { Potato wedges } \\
\text { Crisps } \\
\text { Peanuts and } \\
\text { raisins } \\
\text { Unclear }\end{array}$ & None & $\begin{array}{l}\text { Café/fish } \\
\text { shop } \\
\text { Kitchen table }\end{array}$ & Clear in 7 of 12 photos & 0 & $\begin{array}{l}\text { This child's example shows } \\
\text { a mixture of photographs } \\
\text { recorded by the child and } \\
\text { the parent/carer. This is } \\
\text { the only child who was } \\
\text { photographed eating a } \\
\text { take-away meal which looks } \\
\text { like a café/fish shop, which } \\
\text { means the parent/carer } \\
\text { remembered to take the } \\
\text { camera with them for other } \\
\text { eating occasions. }\end{array}$ \\
\hline
\end{tabular}

Table 2: Example of 2 children's photographic record analysis and types of foods consumed

\section{Discussion}

The recording of young children's dietary consumption can be problematic and relies on the parent/care-giver providing an accurate account of what the child has consumed over a set period. Social desirability bias is common with participants' often reporting higher consumption of 'healthy' foods and less of 'unhealthy' items [19,38,39]. In addition, data may be missed when the child is at school or with other care-givers. Innovative methods which can capture dietary data are being explored and the use of visual methods is becoming increasingly common in dietary consumption recording. The use of digital cameras [23-26] mobile phone cameras [40] or wearable cameras [41] to record dietary intake has been trialled in several studies with older children. Moreover, the sharing of photographic information has become more widespread, especially in digital media with tools and apps such as Facebook, Twitter, Instagram, and so on. This suggests that visual methods have a significant role to play in future research methods.

In the present study, $23(64 \%)$ of the consented children/families provided photographic data and 204 eating occasions were analysed. Eleven families recorded at least 10 images, suggesting they participated in the activity in a substantial way. In contrast, 10 families only provided 5 images or less. Nursery staff reported that parents often forgot about the cameras, especially transferring them between home and preschool, this has been reported as a common issue for this type of study [42]. It was apparent that fruit and vegetables were rarely photographed; a possible explanation is that children only wanted to photograph foods that they enjoyed eating or alternatively the parents may have over-estimated their child's fruit/vegetable consumption in the FAST food diary. 
As previously reported, several children photographed non-food items such as toys, the TV, siblings and a parent's bed. For some children this may have been the first time they had been given permission to freely use a digital camera. Previous studies report that photography allows young children to visually show aspects of their lives that are important to them [42]. Moreover, the types of photographs recorded by 4-year old children are a 'direct expression of their happy acceptance of whatever strikes them as bright or interesting' [43, p.14]. A study by Sharples, Davison [22] which aimed to study and analyse children's behaviour as photographers reported that the youngest children were most likely to photograph personally relevant objects such as toys. Although these types of photographs were not ultimately relevant for the data being collected in the present study, it allowed further insight into the child's home and family life. However, Harper [20] argues that the child's choice of photographs may have been edited by the presence of adults.

Other qualitative studies which have provided participants with digital cameras or a 'SenseCam' [44] to record data, albeit not necessarily diet-related have used the resultant images for 'photo elicitation' [20,44] or 'auto-driven' interviews [42]. The premise being that the interviews are guided by the photographs. Schwartz [45] maintains that it is 'not the photographs which inform, but rather, the analysis of them' (p. 152). Therefore, rather than the researcher imposing their interpretation of the image, the photographer provides their own account. This technique is thought to be suitable for young children as it allows them to retain some control over the interview and shape the topics to be included [42]. A visual methods study conducted with street children in Kampala reported that although some children were less technically adept with the provided cameras, the activity was still particularly useful for stimulating discussion with the children [46]. Ideally this technique would have been employed in the present study; the opportunity to listen to the children's interpretation of their photographs would have provided a fascinating insight into the family's eating habits and the world in which the child inhabited. However, time and financial constraints did not allow for this. A family food practices visual methods study conducted in 2012 reported that this constraint was a limitation; return visits to the children to discuss photographs proved costly both financially and time-wise [19]. The information gathered such as the lack of fruit and vegetable images could prove beneficial for future studies and be used as a discussion tool in interviews and focus groups. Portion size estimation and eating context data too provides additional information and insight into families' child feeding practices which, in turn, informs future interventions with preschool children and their families.

\section{Strengths and limitations}

Although this was a small sample, $64 \%$ of the participating families/children engaged with the task and provided a photographic record of foods consumed over the four day period. A high percentage of the images allowed for the estimation of portion size and eating context. Limitations of the study were the parents forgetting to transfer the camera between the preschool and home and the inability to conduct further analysis of the photos. Ideally, if time and finances had allowed, the children would be have been given the opportunity to explain and discuss the images they captured.

\section{Conclusions}

This study demonstrates that very young children may be capable of using digital cameras and effectively framing a shot. The use of visual methods for collecting dietary data is increasing in the field of health research and may be a useful tool for data collection with children. However, some points are recommended for future research in studies such as these. As suggested by the nursery staff, a meeting with the participants prior to the data collection period may have resulted in a better understanding of the purpose of the data collection. The children too could be involved in a meeting with their teachers and peers to discuss the process and be given the opportunity to handle the cameras prior to data collection. This may have provided the children with more understanding and ownership of the task. Finally, as with most qualitative methods, a degree of reflexivity is essential as visual or creative methods cannot in themselves be seen as providing more accurate or authentic representations [19].

\section{Acknowledgements}

This work is funded by an ESRC studentship awarded to FUSE, the Centre for Translational Research in Public Health. FUSE is a UKCRC Public Health Research Centre of Excellence, supported by ESRC, MRC, NIHR, BHF and CRUK. Thanks are due to the preschool centres, parents and children for their participation in the study. Thanks are also due to Dr Emma Foster for providing writing assistance.

\section{References}

1. Onis M, Blossner M, Borghi E (2010) Gloabal prevalence and trends of overweight and obesity among preschool children. Am J Clin Nutr.

2. National Health Service (2009) National Child Measurement Programme: England, 2008/09 school year, Department of Health and the Department for Schools, Children and Families.

3. Olstad DL, McCargar L (2009) Prevention of overweight and obesity in children under the age of 6years. Appl Physiol, Nutr and Metab 34: 551-70.

4. Osei-Assibey G1, Dick S, Macdiarmid J, Semple S, Reilly JJ, et al. (2012) The influence of the food environment on overweight and obesity in young children: a systematic review. BMJ Open 2.

5. Campbell KJ, Hesketh KD (2007) Strategies which aim to positively impact on weight, physical activity, diet and sedentary behaviours in children from zero to five years. A systematic review of the literature. Obes Rev8: 327-38.

6. Marmot M (2010) Fair Society, Healthy Lives: The Marmot Review. 
7. Field F (2010) The Foundation Years: preventing poor children becoming poor adults - The report of the Independent Review on Poverty and Life Chances, Cabinet Office, Editor. 2010: London.

8. Allen GM (2011) Early Intervention: the Next Steps - an Independent Report to Her Majesty's Government Cabinet Office, Editor: London.

9. Allen GM (2011) Smart Investment, Massive Savings - the Second Independent Report to Her Majesty's Government, Cabinet Office, Editor. 2011: London.

10. Tickell C (2011) The early years: foundations for life, health and learning; an independent review on the early years foundation stage for HM Government, D.f. Education, Editor. 2011.

11. National Health Service (2009) Statistics on obesity, physical activity and diet: England, NHS, Editor. 2009, The Health and Social Care Information Centre.

12. HM Government, PSA Delivery Agreement 12: Improve the health and wellbeing of children and young people, H. Treasury, Editor. 2008, HM Stationery Office: Norwich 40.

13. Alexander R, Armstrong M, Flutter J, Hargreaves L, Harrison D, et al. (2010) Children, their World, their Education: Final Report and Recommendations of the Cambridge Primary Review, ed. R. Alexander. Oxon: Routledge.

14. National Statistics, Provision for children under five years of age in England: January 2012, Department for Education, Editor. 2012, Department for Education: London.

15. Story M, Kaphingst MK, French S (2006) The role of child care settings in obesity prevention. Project Muse 16: 143-68.

16. Birch LL (2006) Child Feeding Practices and the Etiology of Obesity. Obesity 14: 343-4.

17. Barker J, Weller S (2003) “Is it fun?” Developing children centred research methods. Int J Socio and Soci Policy 23: 33-58.

18. Allison J (2007) Giving Voice to Children's Voices: Practices and Problems, Pitfalls and Potentials. Am Anthropol 109: $261-72$.

19. O'Connell R (2013) The use of visual methods with children in a mixed methods study of family food practices. Int J Soc Rese Methodol $16: 31-46$.

20. Harper D (2002) Talking about pictures: a case for photo elicitation. Visual Stud 17: 14-26.

21. Darbyshire PC, MacDougall C, Schiller W (2005) Multiple methods in qualitative research with children: more insight or just more? Qualitative Research 5: 417-36.

22. Sharples M, Davison L, Thomas GV, Rudman PD (2003) Children as Photographers: an Analysis of Children's Photographic Behaviour and Intentions at Three Age Levels. Visual Communication 2: 303-30.

23. Wang D, Kogashiwa M, Kira S (2006) Development of a new instrument for evaluating individuals' dietary intakes. J Am Diet Assoc 106: $1588-93$.

24. Higgins JA, LaSalle AL, Zhaoxing P, Kasten MY, Bing KN, et al. (2009) Validation of photographic food records in children: are pictures really worth a thousand words? Eur J Clin Nutr 63: 1025-33.

25. Lassen AD, Poulsen S, Ernst L, Andersen KK, Biltoft-Jensen A, et al. (2010) Evaluation of a digital method to assess evening meal intake in a free-living adult population. Food Nutr Res 54: 5311.

26. Svensson A, Waling M, Bäcklund C, Larsson C (2012) Overweight and Obese Children's Ability to Report Energy Intake Using Digital Camera Food Records during a 2-Year Study. J Nutr Metab.

27. NHS (2012) Evaluation, Trials and Studies Coordinating Centre - Glossary.

28. Lancaster GA, Dodd S, Williamson PR (2004) Design and analysis of pilot studies: recommendations for good practice. J Eval Clin Pract 10: $307-12$.

29. Schoeller DA, Schoeller DA (2002) Validation of habitual energy intake. Public Health Nutr 5: 883-8.

30. Thompson FE, Subar AF (2008) Dietary Assessment Methodology, in Nutrition in the Prevention and Treatment of Disease, A.N. Coulston, C.J. Boushey, and M.G. Ferruzzi, Editors. Elsevier London 5-46.

31. Roberts K, Flaherty SJ (2010) Review of dietary assessment methods in public health. Natio Obes Observ Oxford.

32. Adamson, A, Carlin L, Wrieden W, Matthews J, Mathers J (2003) FAST: Food Assessment in Schools Tool. Proceedings of the Nutri Soci 62: 84A.

33. Smithers G, Gregory JR, Bates CJ, Prentice A, Jackson LV, et al. (2000) National Diet and Nutrition Survey: young people aged 4 to 18 years. Nutri Bulle 105-11. 34. Gregory J (1995) National Diet and Nutrition Survey: children aged 11/2 to 41/2 years. Volume 1: Report of the diet and nutrition survey. HMSO: London.

35. Griffiths J (2002) The development and validation of a concise, simple tool to assess dietary intake of large groups of primary schoolchildren living in the UK. Human Nutrition Research Centre: Newcastle University.

36. Elo S, Kyngas H (2007) The qualitative content analysis process. J Adv Nurs 62: 107-15.

37. QSR International (2011) NVIVO 9, in QSR International Pty Ltd.

38. Macdiarmid J, Blundell J (1998) Assessing dietary intake: Who, what and why of under-reporting. Nutr Res Rev 11: 231-53.

39. Miller T, Abdel-Maksoud MF, Crane LA, Marcus AC, Byers TE (2008) Effects of social approval bias on self-reported fruit and vegetable consumption: a randomized controlled trial. Nutr J 7: 18.

40. Harray A, Boushey CJ, Pollard CM,Delp EJ, Ahmad Z, et al. (2015) A Novel Dietary Assessment Method to Measure a Healthy and Sustainable Diet Using the Mobile Food Record: Protocol and Methodology. Nutr 7: 5226.

41. Cowburn G, Matthews A, Doherty A, Hamilton A, Kelly P, et al. (2015) Exploring the opportunities for food and drink purchasing and consumption by teenagers during their journeys between home and school: a feasibilty study uwing a novel method. Public Health Nutr 15: 1-11.

42. Clark CD (2008) The Autodriven interview: A photographic viewfinder into children's experience. Visual Sociol 14: 39-50.

43. Thomas AA (2005) Developmental Psychology of Children as Photographers: ESRC Full Research Report, R000238203. ESRC: Swindon.

44. Gemming L, Doherty A, Kelly P, Utter J, Ni Mhurchu C (2013) Feasibility of a SenseCam-assisted 24-h recall to reduce under-reporting of energy intake. Eur J Clin Nutr 67: 1095-9.

45. Schwartz D (1989) Visual Ethnography: Using Photography in Qualitative Research. Qualitat Sociol 12: 119-54.

46. Young L, Barrett H (2001) Adapting visual methods: action research with Kampala street children. Area 33: 141-52. 


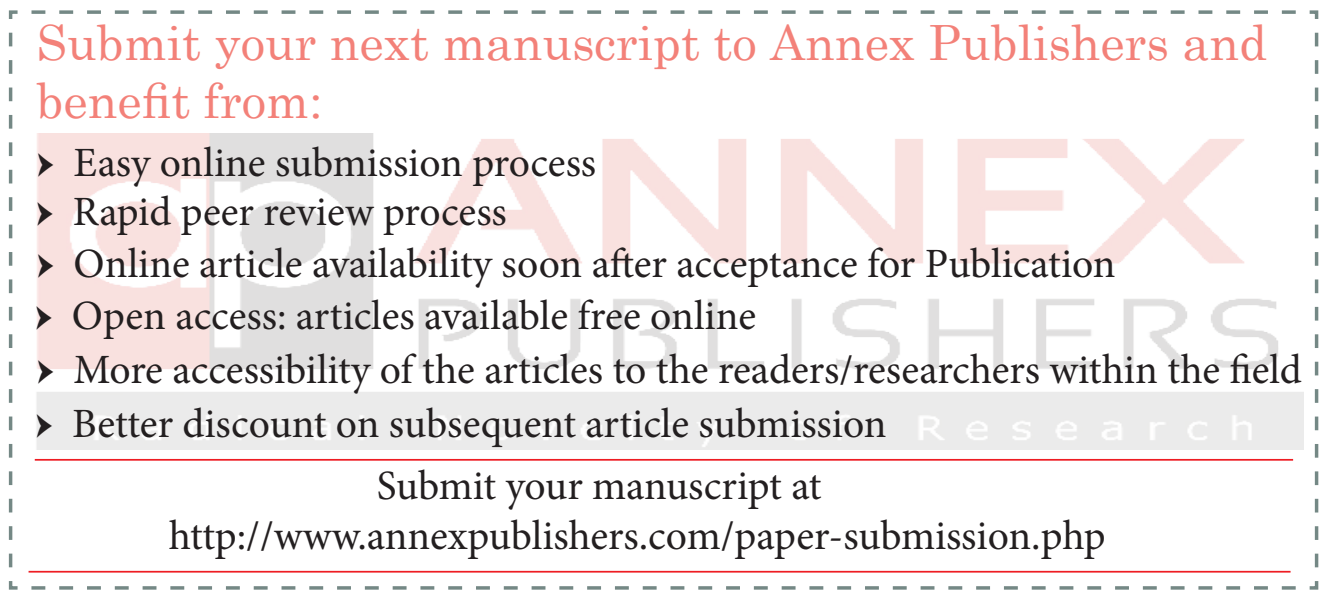

